\title{
Effect of long fibre concentration on low consistency refining of mechanical pulp
}

\author{
Stefan Andersson, Christer Sandberg and Per Engstrand
}

KEYWORDS: Mechanical pulping, low consistency refining, loadability, gap, long fibre concentration.

SUMMARY: The aim of this study was to investigate the influence of long fibre concentration on loadability and pulp properties during LC refining of mechanical pulp. Long fibre concentration was adjusted to three different levels by screen fractionation of the pulp. The three pulps were refined in a single disc pilot scale LC refiner at similar process conditions.

Increased long fibre concentration supported a larger refiner gap and resulted in less fibre cutting at a given specific energy consumption. The higher long fibre concentration probably contributed to a stronger fibre network that maintained a larger refining gap at certain specific energy consumption. Increased long fibre concentration also enabled a higher tensile index increase in the $\mathrm{LC}$ refiner at certain fibre length reduction.

The study supports a process combining LC refining with screen fractionation, where the long fibre fraction is recycled to the refiner feed. This enables a higher loadability and a more effective utilisation of the LC refiner. By using this technology, overall specific energy consumption can be reduced if a larger share of the refining is performed in $\mathrm{LC}$ rather than $\mathrm{HC}$ refining.

\begin{tabular}{l} 
ADDRESSES OF THE AUTHORS: Stefan Andersson \\
(stefan.andersson@holmenpaper.com) and Christer \\
Sandberg (christer.sandberg@holmenpaper.com), \\
Holmen Paper AB, Bravikens pappersbruk, SE-601 88 \\
$\begin{array}{l}\text { Norrköping, Sweden. Per Pngstrand } \\
\text { (per.engstrand@miun.se), FSCN - Mid Sweden }\end{array}$ \\
$\begin{array}{l}\text { University, SE-851 70 Sundsvall, Sweden. } \\
\text { Corresponding author: Stefan Andersson }\end{array}$ \\
\hline
\end{tabular}

\section{Low consistency refining}

Low consistency (LC) refining has become increasingly common in mechanical pulping. LC refiners provide potential to increase the production rate or to decrease the specific energy consumption (SEC) to a certain tensile index (Engstrand et al. 1990; Musselman et al. 1997; Cannell 2002). LC refining of mechanical pulp is typically performed at 4 to $5 \%$ pulp consistency. The fibres flocculate and create networks that support the refiner gap. Depending on pulp consistency, fibre length, stiffness and bonding ability, the network becomes more or less strong and thus affects the gap size differently (Steenberg 1979; Koskenhely et al. 2005; Batchelor et al. 2006; El-Sharkawy et al. 2008; Lundin et al. 2008). To avoid extensive fibre shortening, plate design, gap and specific energy should be optimised (Welch 1999; Mohlin 2006; Luukkonen et al. 2010). Gap relates strongly to fibre development and substantial force can only be imposed on fibre flocs over a rather narrow plate gap window (Martinez, Kerekes 1994). For every pulp type there is an optimum gap to maximise tensile index increase without extensive fibre shortening. A too large gap does not enable enough energy transfer from bars to fibres to create fibrillation, whereas a too narrow gap will extensively shorten the fibres and in the worst case reduce tensile index (Olson et al. 2003; Luukkonen et al. 2010). It has been seen that fractionated pulps are affected differently by LC refining at identical gaps. Fibre length was reduced more (in percent) for pulp with higher average fibre length than pulp with shorter average fibre length (Ferluc et al. 2010).

In LC refining, the most common way of quantifying refining intensity is specific edge load (SEL), expressed as $\mathrm{J} / \mathrm{m}$. SEL tells the amount of net energy applied for each meter of bar crossing (Wultsch, Fluscher 1958; Brecht, Siewert 1966). A study made with selective LC refining of different pulp fractions showed that intensity needs to be carefully adapted to different fibre lengths. Short fibre pulp was more sensitive to fibre shortening with increased refining intensity than long fibre pulp (Koskenhely et al. 2005).

\section{Screen fractionation}

Screens fractionate mainly by fibre length and are fitted with holed or slotted baskets that have either smooth or contoured surfaces. Aperture size, contour height and pulp consistency, together with the speed and design of the rotor, are important factors that affect screen fractionation (Wakelin, Corson 1997; Wakelin, Paul 2000; Olson 2001). Holed screens fractionate more efficiently by fibre length while slotted screens are more efficient in shive removal (Wakelin, Corson 1997; Wakelin et al. 1999; Wakelin, Paul 2000; Olson 2001). Long fibres, shives and contaminating particles are separated as screen reject while fines and short fibres pass the screen apertures and become screen accept.

Combining LC refining and screen fractionation of mechanical pulp is an interesting concept that allows shives and long fibres to be separated in the screen and recirculated into the feed pulp to the LC refiner, Fig 1. The amount of shives is effectively reduced in an LC refiner (Strand et al. 1993; Muenster et al. 2006) and a higher concentration of uncollapsed and long fibres permits a higher refining load (Batchelor et al. 2006; Sandberg et al. 2009).

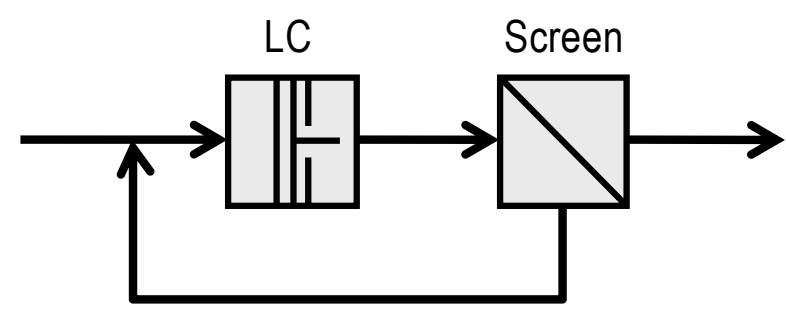

Fig 1. System configuration combining LC refining and screen fractionation. 
It has been shown by Forgacs (1963) that the long fibre fractions of mechanical pulps show less fibrillation and are more rigid than the short fibre fractions. Hypothetically, the long fibre fraction takes the refiner load rather than the whole pulp, which includes fines. This might be an explanation to the higher SEC for reject pulps at certain tensile index increase, as reported by Sandberg et al. (2009). The different fibre morphology would certainly have an effect as well. The specific energy could therefore be expressed as energy per mass of long fibres, $\mathrm{kWh} /$ (ton of long fibres), rather than energy per whole pulp mass (fibres and fines). It is therefore interesting to study the interconnections between different long fibre concentrations and LC refining.

The aim of this pilot scale study was to investigate the influence of long fibre concentration on the refiner loadability and pulp properties during LC refining of mechanical pulp. Long fibre concentration was adjusted by screen fractionation of the pulp.

\section{Materials and methods}

The study was performed in a pilot scale refining loop at Pulp and Paper Centre, University of British Columbia in Vancouver. Trials were performed using a 14 inch single disc LC refiner from Aikawa, powered by a $110 \mathrm{~kW}$ motor. Refiner plates from AFT designed for thermomechanical pulp (TMP) were used for the trials. The plates were 16 inch in diameter and the bar edge length (BEL) was $5.59 \mathrm{~km} / \mathrm{rev}$.

The experiment was designed as three individual trials where refining gap was adjusted to reach five power levels. The trials were performed using three different pulps with different long fibre concentrations. The pulp used in the trials was SPF (spruce, pine and fir) market chemi-thermomechanical pulp (CTMP) produced at Quesnel River Pulp Mill in British Columbia, Canada.

Pulp suspensions were prepared in an insulated tank by suspending dry pulp in approximately 2000 litres of water at $63^{\circ} \mathrm{C}$. Consistency was measured and adjusted by adding water or dry pulp while suspensions were prepared. Prior to conducting trials, the pulps were agitated for four hours. The pulps held a temperature between 55 and $61^{\circ} \mathrm{C}$ when the trials were initiated.

In order to modify the fibre fraction distribution, $50 \mathrm{~kg}$ dry weight pulp was first fractionated in a screen and long and short fibre fractions were collected in separate tanks. Bauer-McNett fibre fraction analyses were performed according to SCAN-CM 6:05 for feed pulp and long and short fibre fractions. Screening was conducted using a laboratory MR 8 pressure screen with a $1 \mathrm{~mm}$ smooth holed basket. The pulps were then dewatered in two hanging 750 litres plastic woven tote bags. The first drainage water was recirculated to put fines back into the pulp until a fibre mat had formed and only clear water drained from the tote bags. Accept and reject pulps were then separately mixed with a batch of market pulp and diluted with hot water to prepare a short fibre enriched pulp (SF) and a long fibre enriched (LF) pulp. Unmodified market pulp was used as reference pulp.
The first samples in each trial were collected from the refiner outlet at no-load and samples were thereafter collected at each specific energy level. Inlet pulps from each trial were analysed regarding fibre fractions. Long fibre concentrations (presented in $\mathrm{g} / \mathrm{kg}$ ) were calculated by multiplying pulp consistency by long fibre content (R14+R28).

Gap measurements were recorded from the refiner control system during the trials. Furthermore, inlet and outlet pressure, pulp temperature, refining power and specific refining energy were recorded. The refiner was running at $1200 \mathrm{rpm}$ (corresponding to peripheral speeds of $14.8-25.5 \mathrm{~m} / \mathrm{s}$ at inner and outer refining zone diameter respectively) and flow rate was held constant at 200 litres per minute. Pulp samples for laboratory analysis were taken at each power level. Reference and LF pulps were refined at five power levels while SF pulp had to be cut short after four power levels because of a too narrow plate gap.

After completing the experiment, samples were treated with biocide (Fennosan 1750C), dewatered and sent by air freight to Braviken paper mill in Sweden for analysis. After 40 days of storage at $-18{ }^{\circ} \mathrm{C}$, the samples were analysed using hot disintegration according to ISO 52633. CSF was tested by ISO 5267-2 standard while shive content and fibre characteristics were measured with a Eurocon PulpEye. Hand sheets were made with Rapid Köthen sheet former according to ISO 5269-2. Hand sheets were tested for specific light scattering using ISO 9416 standard, and tensile index using ISO 1924-2 standard.

\section{Results and discussion}

Presented pulp properties are averages from triple analyses of pulp samples. Drawn lines in figures are best fitted curves for each individual plot and should be regarded as guidance when interpreting the figures rather than functions. Error bars in the figures show 95\% confidence interval of the mean for each pulp type.

\section{Screen fractionation}

Screen accept contained significantly less long fibres and more fines than reject. The amounts of long fibres and fines in feed pulp were in-between accept and reject pulps, Table 1.

Table 1. Fibre fraction classification of market CTMP before and after screening.

\begin{tabular}{lccc}
\hline Fractions content (\%) & Feed & Accept & Reject \\
\hline R14 & 4.2 & 0.3 & 7.3 \\
R28 & 32.9 & 16.7 & 42.4 \\
R48 & 20.7 & 21.2 & 22.3 \\
R100 & 10.4 & 13.6 & 10.7 \\
R200 & 6.4 & 8.6 & 5.3 \\
P200 & 25.4 & 39.6 & 12.1 \\
Fines content (R200+P200) & 31.8 & 48.2 & 17.4 \\
Long fibre content (R14+R28) & 37.1 & 17.0 & 49.7 \\
\hline
\end{tabular}




\section{Refining process aspects}

A loadability curve illustrates how the refiner power changes as a function of the refining gap (Batchelor et al. 2006; El-Sharkawy et al. 2008). Fig 2 shows how gross power increased in each trial with decreasing refiner gap. It is obvious that SF pulp, with the lowest long fibre concentration, required the smallest gap to reach a certain power while LF pulp, with the highest long fibre concentration, required the largest gap. The increase in power at a certain decrease in gap was the steepest for LF pulp while SF pulp rendered the flattest trend. This was well in accordance with previous findings (El-Sharkawy et al. 2008). The higher long fibre concentration in LF pulp probably contributed to a stronger fibre network than the pulps with lower long fibre concentration. A stronger fibre network can be an explanation to the larger gap in LF pulp.

\section{Pulp properties}

Table 2 shows feed pulp properties and refining conditions from the three trials.

With decreasing gap, and thereby increasing SEC, tensile index initially increased, reached a maximum and thereafter decreased. Fig 3 demonstrates the tensile index development with decreasing gap. The three pulps showed similar trends and reached tensile index optima at gaps around $0.2 \mathrm{~mm}$.

LF pulp had higher tensile index increase than reference and SF pulp, Fig 4. These were expected results which imply that there is an individual optimum level of refining for each pulp type. There was no indication of higher energy consumption for the LF pulp, as seen earlier in full scale (Sandberg et al. 2009). These trials could therefore not support the hypothesis that SEC should be based on the mass of fibres rather than the mass of whole pulp.

As fibres are refined, they are also shortened to a certain degree depending on refining conditions, such as SEC, gap and intensity (Welch 1999; Koskenhely et al. 2005; Mohlin 2006). Fig 5 shows how fibre length was shortened with increasing SEC for the three pulps in this study. Relative fibre length illustrates the degree of fibre shortening after refining and was calculated by outlet pulp fibre length divided by inlet pulp fibre length. Fibre length was shortened slightly more for SF pulp than reference and LF pulp.

Table 2. Refining conditions for the three different pulps.

\begin{tabular}{lccc}
\hline Pulp & Reference & SF & LF \\
\hline Consistency $(\%)$ & 3.3 & 3.4 & 3.5 \\
CSF $(\mathrm{ml})$ & 133 & 102 & 164 \\
Temperature $\left({ }^{\circ} \mathrm{C}\right)$ & 61.1 & 57.2 & 55.2 \\
Fines (R200+P200) & 30.0 & 35.7 & 28.1 \\
Long fibres (R14+R28) & 38.8 & 32.0 & 40.4 \\
Long fibre conc. $(\mathrm{g} / \mathrm{kg})$ & 12.8 & 10.9 & 13.9 \\
Shive content $(\# / \mathrm{g})$ & 313 & 282 & 281 \\
Number of samples & 6 & 5 & 6 \\
SEL $(\mathrm{J} / \mathrm{m})$ & $0.18-0.39$ & $0.16-0.36$ & $0.17-0.45$ \\
Net SEC (kWh/adt) & $43-95$ & $37-82$ & $35-101$ \\
Gross SEC (kWh/adt) & $47-141$ & $46-124$ & $45-144$ \\
Production rate (adt/h) & $0.44-0.47$ & $0.45-0.49$ & $0.46-0.54$ \\
\hline
\end{tabular}

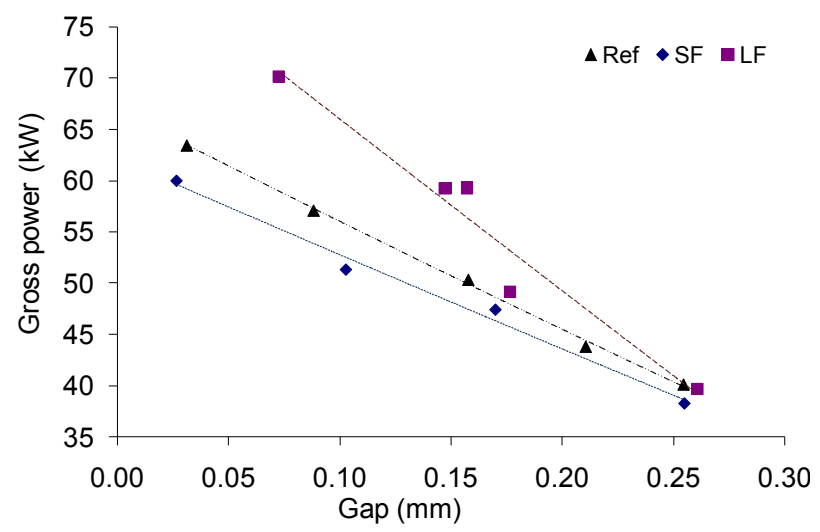

Fig 2. Gross power plotted against gap.

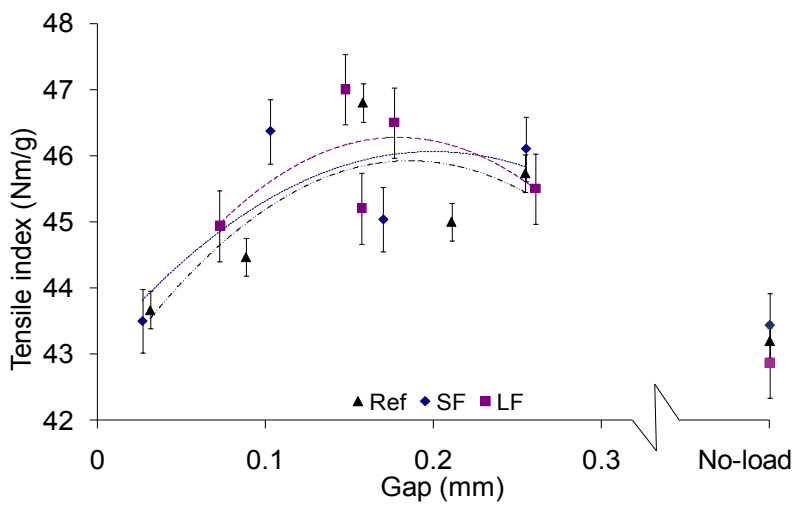

Fig 3. Tensile index versus refiner gap.

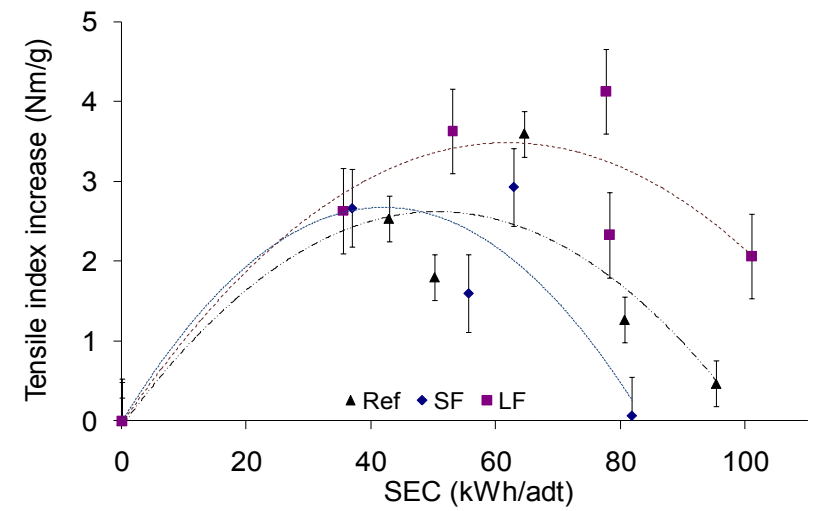

Fig 4. Tensile index increase versus specific energy consumption.

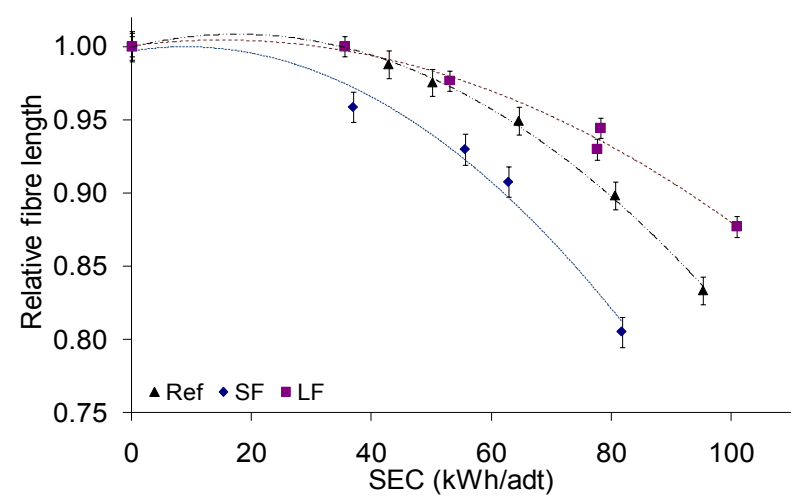

Fig 5. Relative fibre length (outlet pulp fibre length divided by inlet pulp fibre length) versus specific energy consumption. 


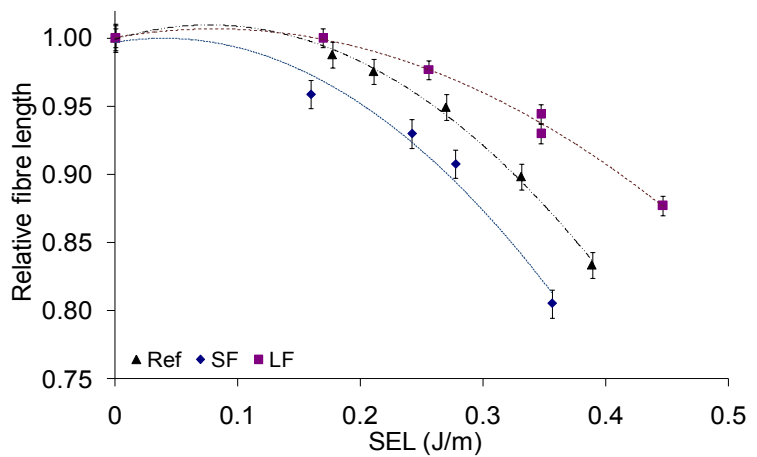

Fig 6. Relative fibre length (outlet pulp fibre length divided by inlet pulp fibre length) plotted against specific edge load.

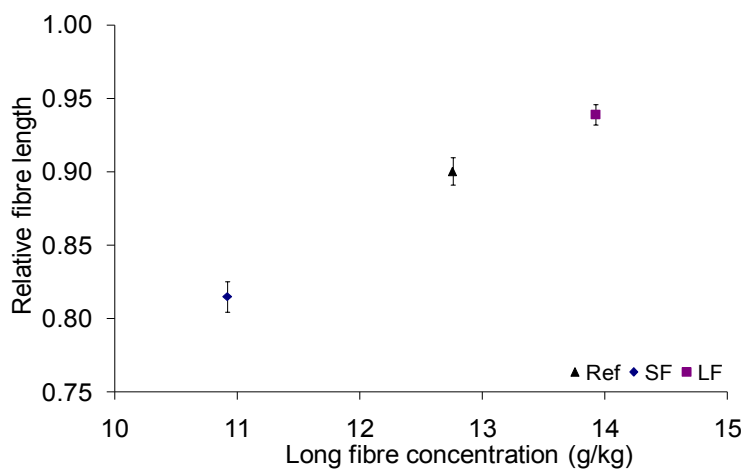

Fig 7. Relative fibre length (outlet pulp fibre length divided by inlet pulp fibre length) in relation to long fibre concentration for pulps refined at $80 \mathrm{kWh} / \mathrm{adt}$, interpolated from data in Fig 5.

Refining intensity is recommended to be as high as possible without cutting fibres. That enables fibre development with the smallest possible amount of bar impacts (Salmén et al. 1997). Specific edge load (SEL) is a common way of quantifying refining intensity and takes into account net power, BEL and rotational speed. SEL tells the net energy applied to each meter of bar crossing, expressed as $\mathrm{J} / \mathrm{m}$.

Fig 6 describes how the degree of fibre shortening differed between trials with increasing SEL. SF pulp was the most sensitive to higher SEL. Reference pulp was less sensitive than SF pulp while LF pulp was the least affected by increasing SEL. This shows that SEL is not sufficient to alone characterise the refining action and that fibre properties need to be considered. One such theory is the C-factor (Kerekes 1990).

The results agree well with earlier studies where it has been argued that gap, intensity and SEC strongly relates to the development of fibre properties, such as tensile strength and fibre length (Welch 1999; Olson et al. 2003; Koskenhely et al. 2005; Luukkonen et al. 2010). The higher relative fibre shortening in SF pulp is different from the findings of Ferluc et al. (2010), where LF pulp had the highest relative fibre shortening.

The long fibre concentration can explain the higher loadability of LF pulp. In Fig 7, relative fibre length at 80 $\mathrm{kWh} / \mathrm{adt}$ for each pulp is plotted as a function of long fibre concentration. The values are interpolated to equal SEC from data shown in Fig 5. The figure indicates a possible correlation between fibre shortening and long fibre concentration of the pulp.

The results presented in this paper support the earlier mentioned combination of LC refining and screening as an interesting concept, Fig 1. Combining LC refining and screen fractionation enables efficient shive removal and a higher load in the refiner. The higher load is possible, probably because of a stronger fibre network in the gap. This allows a more efficient utilisation of LC refiners in the production of mechanical pulp. Higher SEC in LC refining will reduce the overall SEC to certain tensile index since LC refining is more energy efficient than $\mathrm{HC}$ refining.

\section{Conclusions}

Increased long fibre concentration enabled higher loadability, and thereby higher tensile index increase, in the LC refiner at certain fibre length reduction.

Long fibre enriched pulp seemed to form a stronger fibre network, that maintained larger refining gap at certain specific energy consumption, compared with short fibre pulp. The larger gap probably contributed to the lower amount of fibre shortening in long fibre pulp.

Long fibre enriched pulp was less sensitive to high specific edge load. These results support the idea of combining LC refining and screen fractionation, where the long fibre fraction is fed back to the feed of the LC refiner.

Increased long long fibre concentration allows a more efficient utilisation of LC refiners in mechanical pulping. Consequently, the overall specific energy consumption can be reduced if a larger part of the refining is performed in $\mathrm{LC}$ refining rather than in $\mathrm{HC}$ refining.

\section{Acknowledgements}

This study was financially supported by Holmen Paper $A B$ and Hellströms stipendiefond. Equipment, personnel and valuable time were provided by Pulp and Paper Centre at the University of British Columbia in Vancouver, Canada. Authors gratefully acknowledge James Olson, Antti Luukkonen, Jens Heymer, Sean Delfel and George Soong for enabling pilot scale trials at Pulp and Paper Centre. Thanks also to Marie Nilzén and Cristine Saville for analysing pulp samples and to Erik Nelsson, Janosch Schenk, Rainer Grathwohl and Brita Timmermann for valuable input to the manuscript.

\section{Literature}

Batchelor, W., Lundin, T. and Fardim, P. (2006): A Method to Estimate Fiber Trapping in Low-Consistency Refining, Tappi J., 5(8), 31-36.

Brecht, W.J. and Siewert, W. (1966): Zur theoretischtechnischen Beurteilung des Mahlprozesses moderner Mahlmaschinen, Das Papier, 20(1), 4-14.

Cannell, E. (2002): Low consistency refining of TMP, Solutions!, 85(12), 30-32.

El-Sharkawy, K., Haavisto, S., Koskenhely, K. and Paulapuro, H. (2008): Effect of fiber flocculation and filling design on refiner loadability and refining characteristics, BioResources, 3(2), 403-424. 
Engstrand, P., Hammar, L-Å., Htun, M.T., Pettersson, R.L. and Svensson, B.N. (1990): Framställning av mekanisk och kemimekanisk massa i två steg, Svenskt patent 8801731-4, 461 103, filed May 6, 1988, issued January 8, 1990.

Ferluc, A., Lanouette, R., Bousquet, J.P. and Bussiere, S. (2010): Optimum refining of TMP pulp by fractionation after the first refining stage, Appita J., 63(4), 308-314.

Forgacs, O.L. (1963): The characterization of mechanical pulps, Pulp Paper Mag. Can., Convention Issue, pp. 89-118.

Kerekes, R.J. (1990): Characterization of pulp refiners by a Cfactor, Nord. Pulp Paper Res. J., 5(1), 3-8.

Koskenhely, K., Paulapuro, H., Ämmälä, A. and Jokinen, H. (2005): Effect of refining intensity on pressure screen fractionated softwood kraft, Nord. Pulp Paper Res. J., 20(2), 169-175.

Lundin, T., Batchelor, W. and Fardim, P. (2008): Fibre trapping in low-consistency refining: new parameters to describe the refining process, Tappi J., 7(7), 15-21.

Luukkonen A., Olson, J. and Martinez, M. (2010): Low consistency refining of Mechanical Pulp, Effect of Gap, Speed and Power, J. Pulp Paper Sci., 36(1-2), 28-34.

Martinez, D.M. and Kerekes, R.J. (1994): Forces on fibres in low-consistency refining, Tappi J., 77(12), 119-123.

Mohlin, U.B. (2006): Refining intensity and gap clearance, 9th PIRA Intl. Refining Conf., Vienna, Austria, 22-23 February, 2006.

Muenster, H., Ferritsius, O., Lecourt, M. and Petit-Conil, M. (2006): High temperature LC/MC refining offers TMP energy advantages, Pulp Paper, 79(7), 44-49.

Musselman R, Letarte, D. and Simard, R. (1997): Third stage low consistency refining of TMP for energy savings and quality enhancement, PIRA $4^{\text {th }}$ Int. Refining Conf., 1997, Fuiggi, Italy, pp. 141-147.

Olson, J.A. (2001): Fibre length fractionation caused by pulp screening, slotted screen plates, J. Pulp Paper Sci., 27(8), 255261.

Olson, J.A., Drozdiak, J., Martinez, M., Garner, R., Robertson, A.G. and Kerekes, R. (2003): Characterizing fibre shortening in low-consistency refining using a comminution model, Powder Technology, vol. 129, pp. 122-129.

Salmén, L., Dumail, J.F. and Uhmeier, A. (1997): Compression behaviour of wood in relation to mechanical pulping, Int. Mech. Pulping Conf., Stockholm, Sweden, 1997, SPCl, Stockholm, Sweden, pp. 207-211.

Sandberg, C., Sundström, L. and Nilsson, L. (2009): Potential of low consistency refining of TMP - mill evaluation, Int. Mech. Pulping Conf., Sundsvall, Sweden, May 31- June 4 , 2009, Kopieringen Mid Sweden University, Sundsvall, Sweden, pp. 186-189.

Steenberg, B.K. (1979): Oozing and consolidation (scalar and vector forces) in fibre/water systems (under compression), Pap. Technol. Ind., 20(8), 282-285.

Strand, B.C., Falk, B., Mokvist, A. and Jackson, M. (1993): The effect of production rate on specific energy consumption in high consistency chip refining, Int. Mech. Pulping Conf., Oslo, Norway, pp. 143-151.
Wakelin, R.F. and Corson, S.R. (1997): TMP long fibre fractionation with pressure screens, Pulp Paper Can., 98(12), 179-182.

Wakelin, R.F., Dahlqvist, G.K. and Isaksen, J.E. (1999): Balancing the roles of refiners, screens and hydrocyclones in the production of high quality mechanical pulps, 53 $3^{\text {rd }}$ Ann. Appita Conf., Rotorua, New Zealand, Appita Inc, Australia, pp. 509-517.

Wakelin, R.F. and Paul, S.T. (2000): Effects of some process variables on screen fractionator performance, $54^{\text {th }}$ Ann. Appita Conf., Melbourne, Australia, Appita Inc, Australia, pp. 153-160.

Welch, L.V.S. (1999): Low Consistency Refining of Mechanical Pulps, Ph.D. thesis, Dep. Chem. Eng., University of British Columbia, Canada.

Wultsch, V.F. and Flucher, W. (1958): Der Eshcer-WyssKleinrefiner als Standard-Prüfgerät für modern Stoffaufbereitungsanlagen, Das Papier, 12(13/14), 334-342.

Manuscript received August 31, 2011 Manuscript accepted May 4, 2012 